\title{
Assessment of the influence of additives in concrete by the Raman spectroscopy method
}

\author{
Gennadiy Ovcharenko ${ }^{1}$, Ekaterina Ibe $^{2, *}$, and Artem Viktorov ${ }^{1}$ \\ ${ }^{1}$ Polzunov Altai State Technical University, Department of Building and technologies, 656038, \\ Barnaul, Russia \\ ${ }^{2}$ Khakas Technical Institute, Siberian Federal University, Department of Building, transport and \\ mechanical engineering, 655017, Abakan, Russia
}

\begin{abstract}
The effect of nano $\mathrm{SiC}$ additives with a particle size less than $50 \mathrm{~nm}$, carbon black with a specific surface of about $80 \mathrm{~m}^{2} / \mathrm{g}, \mathrm{SiO}_{2}$ and $\mathrm{Al}_{2} \mathrm{O}_{3} \mathrm{zol}, \mathrm{AlCl}_{3}, \mathrm{FeCl}_{3}$ solutions on the composition of silicon-oxygen anions in the pure $\mathrm{C}-\mathrm{S}-\mathrm{H}$ phase and hydrated cement was studied. The mixture was pressed at a specific pressure of $100 \mathrm{MPa}$ and tested for compressive strength after 1, 7 and 28 days of normal aging. The Raman spectroscopy method was used to determine the composition of siliconoxygen anions (SOA) in the C-S-H phase of cement and compared it with the strength of the stone, as well as with the SOA composition in the pure $\mathrm{C}-\mathrm{S}-\mathrm{H}$ phase. It was found that the initial powder of the C-S-H phase mainly contains isolated $\mathrm{Q}^{0}$ and terminal $\mathrm{Q}^{1}$ tetrahedra $\left[\mathrm{SiO}_{4}\right]$. Pressing the powder at $100 \mathrm{MPa}$ leads to the advanced formation of chains of crosslinking $\mathrm{Q}^{2}$ and $\mathrm{Q}^{3}$ tetrahedra. The addition of silica to $\mathrm{C}-\mathrm{S}-\mathrm{H}$ promotes maximum chain formation from $\mathrm{Q}^{2}$. The Raman spectrum of C-S-H with silica zol is identical to the spectrum of hydrated cement. Iron chloride prevents the formation of extended chains of silicon-oxygen tetrahedrons. Carbon-containing nano-additives significantly alter the spectrum of C-S$\mathrm{H}$ calcium substructures.
\end{abstract}

\section{Introduction}

Chemical and mineral additives to concrete have been studied in sufficient detail [1-3]. This was especially true in the era of high water-cement ratio concrete in the absence of superand hyperplasticizers. As is known, many chemical additives (in addition to gypsum) interact with aluminates and aluminoferrites of cement, form additional amounts of AFt and AFm phases that bind a large amount of water $\left(32 \mathrm{H}_{2} \mathrm{O}, 12 \mathrm{H}_{2} \mathrm{O}\right)$, which significantly increases the volume of the solid phase and reduces the porosity of the stone with the resulting improvement all operational characteristics of concrete.

In recent years, there has been increased interest in certain chemical and nano-additives, especially at concentrations less than $1 \%$, which can significantly improve the properties of cements and concrete [4-10]. Physicochemical effects of their action, as a rule, are not recorded by standard analysis methods in the form of X-ray, DTA, IR spectroscopy. With a

\footnotetext{
* Corresponding author: katerina.ibe@ mail.ru
} 
low content of additives, there is no need to talk about a significant change in the fraction of the solid phase and porosity of the stone.

In this regard sometimes the question arises about the reasons for the significant change in the properties of cements and concrete, the answer to which is often formulated hypothetically.

One of the reasons for changing the properties of concrete in these cases may be a change in the characteristics of the main phase of the cement stone - C-S-H gel. The C-S-H phase occupies about $60 \%$ of the volume in cement stone and determines many of its properties [3]. According to the physicochemical classification, this phase is a solid gel formed from a sol of C-S-H particles in water due to the partial polymerization of siliconoxygen anions (SOA) and the "crosslinking" of particles into a single framework. It should be noted that far from all particles are "crosslinked" and at all cement hardening periods they are also "bonded" by the Van der Waals surface interaction forces [11]. Primary C-S$\mathrm{H}$ particles cannot grow into crystals due to the crystal chemical features of their structure [12]. Therefore, C-S-H gel is characterized by a high specific surface of $1000 \mathrm{~m}^{2} / \mathrm{g}$ (or 10 million $\mathrm{cm}^{2} / \mathrm{g}$ ) for the initial zol particles and up to $250-300 \mathrm{~m}^{2} / \mathrm{g}$ for the gel during the concrete service life, which determines its high "sticking, binding" ability [11, 13].

It is also believed that the more fully the polymerization process of SOA (lasting the entire service life of concrete), the stronger and more rigid the structure that remains in the form of a C-S-H phase.

Based on the fact that numerous additives for concrete can affect the C-S-H phase of cement, including the compositional characteristics of its silicon-oxygen anions, the control of this process is an important task of building materials science.

The aim and subject of research in this work is to establish a relationship between the type of some additives in concrete and the distribution of silicon-oxygen anions in the C-S$\mathrm{H}$ cement phase in conjunction with the contact strength of hydrated cement stone.

\section{Materials and methods}

In this study, fully hydrated Portland cement CEM I/42.5B by company "Iskitimcement" was used. Hydration was carried out by 100 hours of steaming samples from a suspension with $\mathrm{W} / \mathrm{C}=0.5$ at $80^{\circ} \mathrm{C}$. After hardening, the cement stone was crushed, ground and sieved through a sieve No.008. The pure C-S-H phase with a basicity valued 1 was synthesized from Aerosil A-300 and lime by wet grinding of raw materials according to the procedure [14]. The suspension was dried at $60{ }^{\circ} \mathrm{C}$ in a stream of nitrogen to obtain a powder. As additives for both $\mathrm{C}-\mathrm{S}-\mathrm{H}$ and hydrated cement, nano-additives and chemical reagents widely discussed in the literature were used: Leksil silica zol of Kazan Compass Scientific and Technical Center with a mass concentration of silicon dioxide of 29-31\% and an average particle size of about $30 \mathrm{~nm}$; alumina zol of the same manufacturer with a basic substance content of $19-21 \%$ and a particle size of about $80 \mathrm{~nm}$; nano silicon carbide of the Chinese company "SAT NONO TECHNOLOGY MATERIAL CO., LTD" with SiC particle size of not more than $50 \mathrm{~nm}$ and a basic substance content of not less than $99 \%$; aluminum chloride - according to GOST 3759-75; iron chloride - according to GOST 414774; carbon technical grade P324 according to GOST 7885-86.

From powders of hydrated cement (HC) and C-S-H with the addition of $10 \%$ distilled water or additive solutions, samples were pressed in metal form under a specific pressure of 20, 60 and $100 \mathrm{MPa}$ with a diameter and height of 30 and $50 \mathrm{~mm}$. Solid additives were introduced prior to pressing with stepwise averaging in a porcelain mortar. Water-soluble (dilutable) additives were introduced with compression water. 
Samples for compressive strength were tested by 1 day after pressing. Some samples were kept under normal conditions for 7 and 28 days and then tested for compressive strength.

The phase composition was studied by standard methods of X-ray, DTA, IR spectroscopy, and Raman spectroscopy. Raman spectra were obtained on a Bruker Fourier spectrometer RFS-100.

\section{Results}

As can be seen from Figures 1 and 2, the contact strength of hydrated cement (HC) substantially depends on the type of additives introduced to it after hydration and pressing pressure. Moreover, while when pressing at $20 \mathrm{MPa}$ all additives impair contact strength at an early age, then at $100 \mathrm{MPa}$ the opposite is the case (Figure 1). The most noticeable positive effect of the addition of iron chloride.

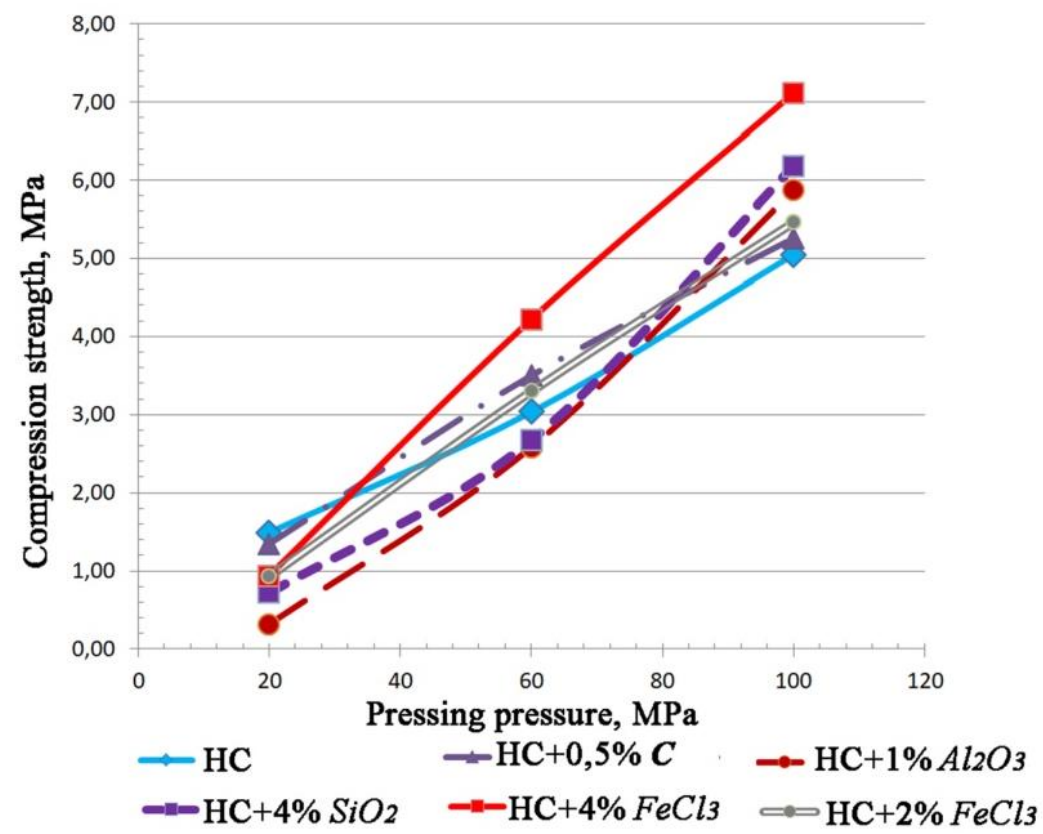

Fig. 1. Compressive strength of pressed samples of hydrated cement (HC) and additives aged 1 day under normal conditions.

At 28 days of normal aging (Figure 2), the effect of increasing strength is enhanced. Characteristically, a noticeable increase is provided by the addition of $0.5 \%$ carbon, $1 \%$ silicon carbide, which, according to X-ray, remain in a free state.

The results of phase analysis showed that these additives are mainly absorbed by the phases of hydrated cement, with the exception of carbon and silicon carbide. Most of the Xray, DTA and IR spectroscopy curves were of the same type, characterized only the main phases of hydrated cement and did not show noticeable differences depending on the type of additive. And only Raman spectroscopy showed significant differences in the composition of silicon-oxygen anions in the C-S-H phase, depending on the type of additive. 


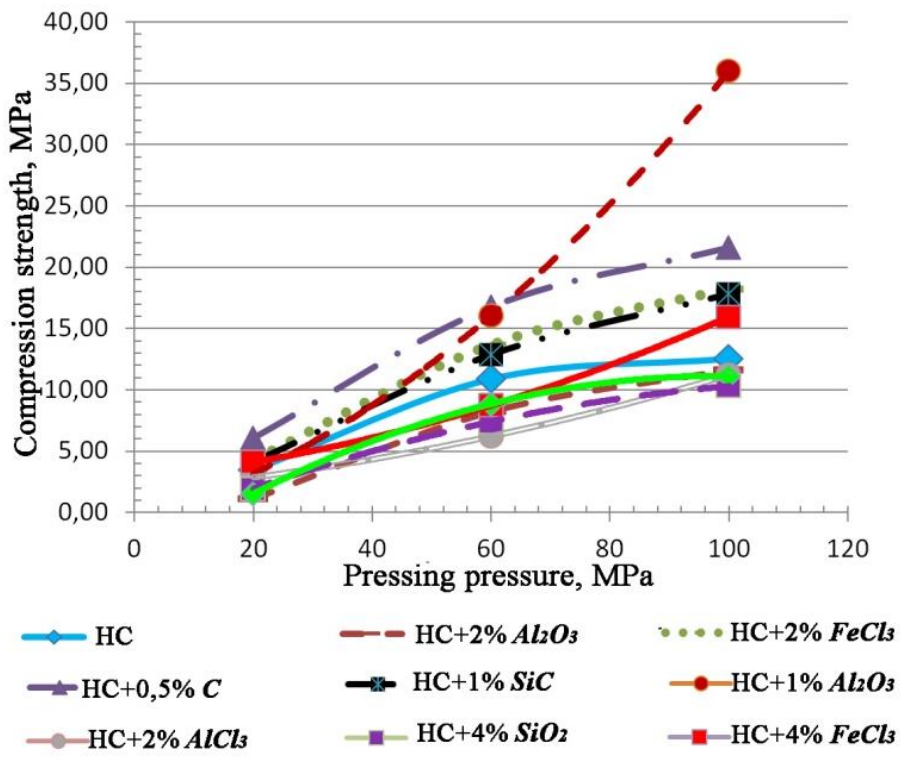

Fig. 2. Compressive strength of pressed samples of hydrated cement and additives aged 28 days under normal conditions.

To interpret the data of Raman scattering, Fig. 3 shows a diagram of varieties of siliconoxygen tetrahedra and their designation in the C-S-H phase or in its analogue C-A-S-H. It indicates the designations of silicon-oxygen tetrahedrons accepted in the scientific community. $\mathrm{Q}^{0}$ - solitary unrelated to others. $\mathrm{Q}^{1}$ - terminal tetrahedra of chains. $\mathrm{Q}^{2}$ are linked to two other tetrahedra in a chain. In addition, here are designated: $\mathrm{Q}^{2}$ - connected with the diorthogroup $\left[\mathrm{Si}_{2} \mathrm{O}_{7}\right]$ - paired or $\mathrm{Q}^{2} \mathrm{~b}$ - bridge tetrahedron. $\mathrm{Q}^{2}(1 \mathrm{Al})$ - associated with two tetrahedra, one of which is with an aluminum cation. $\mathrm{Q}^{3}-$ linked simultaneously with three tetrahedra stitching the chain.

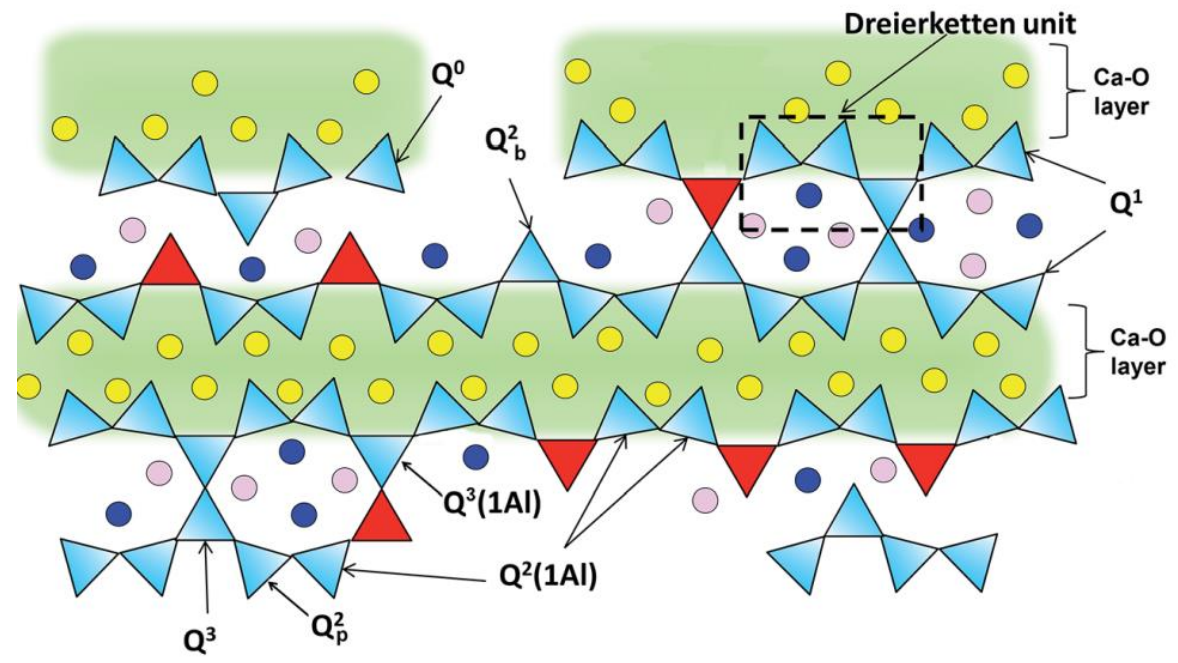

Fig. 3. Schematic illustration of silicon-oxygen radicals in C-A-S-H according to [15]. 
The peaks in the Raman spectra were used to identify one or another variety of tetrahedra in the structure of C-S-H. In order to understand the spectra of hydrated cement, it is first necessary to consider them in the pure $\mathrm{C}-\mathrm{S}-\mathrm{H}$ phase.

In the initial C-S-H powder (Figure 4, denoted by C-S-H 1:1), the presence of mainly terminal $\mathrm{Q}^{1}$ tetrahedra and single $\mathrm{Q}^{0}$ tetrahedra at $820 \mathrm{~cm}^{-1}$ is observed. The spectrum indicates not large fluctuations in the symmetric stretching for the $\mathrm{C}-\mathrm{O}$ groups in $\mathrm{CaCO}_{3}$, as well as stretching vibrations for the Ca-O calcium polyhedra at 1500 and $1625 \mathrm{~cm}^{-1}$ [15].

Compression of the initial powder at sufficiently high pressures of $100 \mathrm{MPa}$ noticeably changes the pattern of the arrangement of silicon-oxygen tetrahedra. If the powder mainly contained terminal tetrahedra $\mathrm{Q}^{1}$ and isolated $\mathrm{Q}^{0}$, then after pressing (denoted by $\mathrm{C}-\mathrm{S}-\mathrm{H}$ $100 \mathrm{M})$, the oxygen chains lengthened and the fraction of neighboring $\mathrm{Q}^{2}$ tetrahedra increased noticeably.

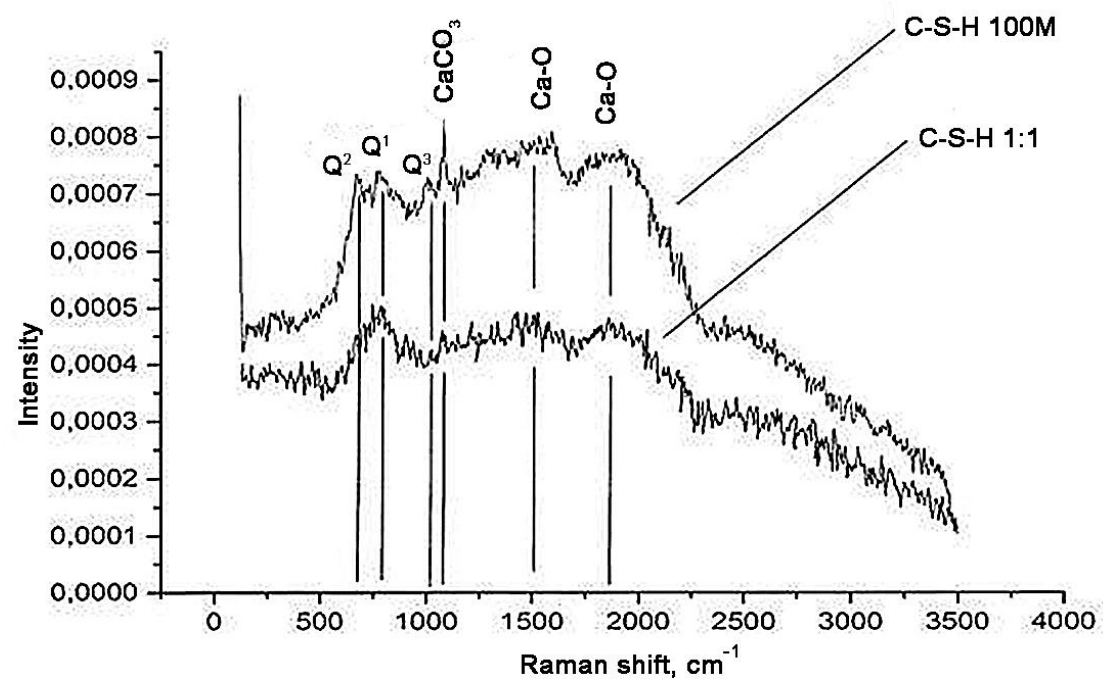

Fig. 4. Raman spectra of the original powder C-S-H and its own, pressed at $100 \mathrm{MPa}$.

In addition, crosslinking $\mathrm{Q}^{3}$ tetrahedra appeared additionally. The content of $\mathrm{C}-\mathrm{O}$ groups in $\mathrm{CaCO}_{3}$ also increased due to moistening and carbonization of the compacts (which was also noted by X-ray and DTA methods). The carbonate phase was vaterite. More distinct fluctuations of calcium polyhedra are noted. That is, changes in the fine structure of the $\mathrm{C}-\mathrm{S}-\mathrm{H}$ phase during pressing are significant. This despite the fact that the density of the compacts $\left(1.3 \mathrm{~g} / \mathrm{cm}^{3}\right)$ is significantly behind the density of the C-S-H phase in the cement stone (at least $2.2 \mathrm{~g} / \mathrm{cm}^{3}$ ), i.e. with even more pressing, the crosslinking of the tetrahedron chains should increase.

The addition of silica sol to C-S-H before pressing in an amount of $4 \%$ for $\mathrm{SiO}_{2}$ changed the picture even more significantly (Figure 5). The content of $\mathrm{Q}^{2}$ tetrahedra becomes prevailing with a noticeable content of terminal tetrahedra $\mathrm{Q}^{1}$, the proportion of crosslinking $\mathrm{Q}^{3}$ tetrahedra increases slightly. 


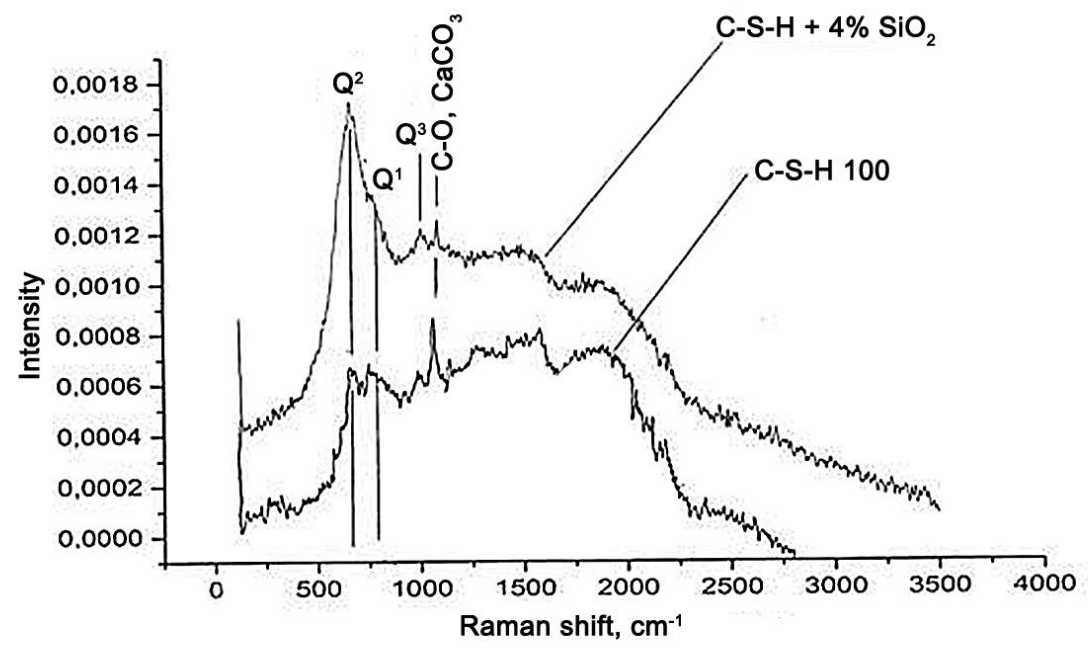

Fig. 5. Raman spectra of C-S-H pressed at $100 \mathrm{MPa}$ and with silica zol $\left(\mathrm{SiO}_{2}\right)$.

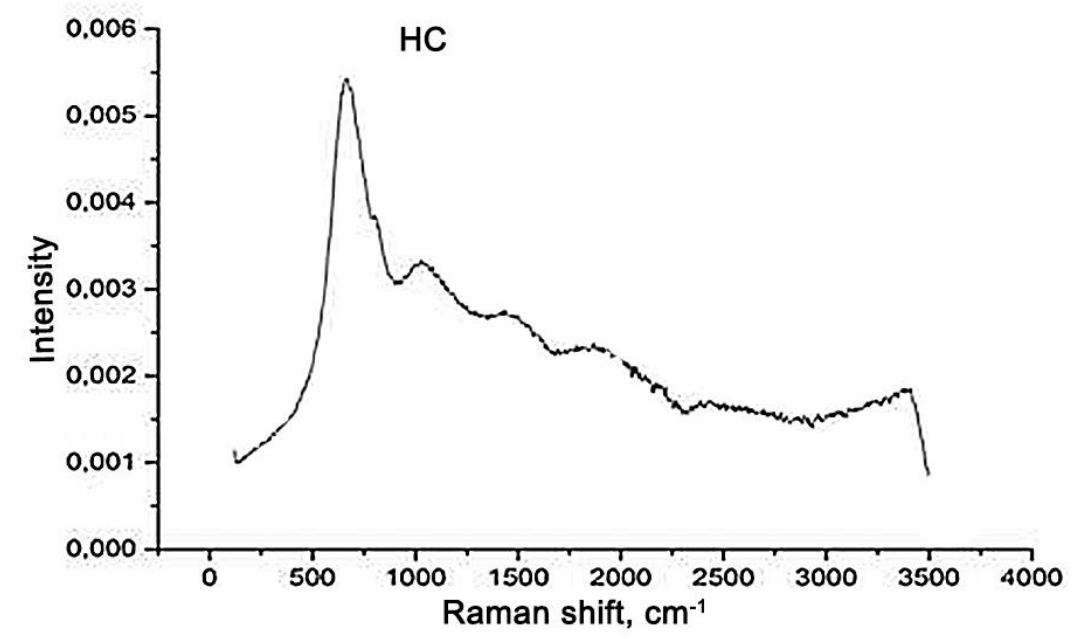

Fig. 6. Raman spectra of fully hydrated Portland cement (HC).

The Raman spectrum of fully hydrated cement reflects the patterns described above. The maximum content of tetrahedra is $Q^{2}$, then $Q^{1}$. In the region of the Raman shift of 1000 $\mathrm{cm}^{1}$, vibrations of elements of several phases are noted. These are ettringite, monosulfate and $\mathrm{Q}^{3}$. In the shear region of 1500 and $2000 \mathrm{~cm}^{-1}$, there are oscillations of portlandite and calcium polyhedra in the $\mathrm{C}-\mathrm{S}-\mathrm{H}$ phase. 


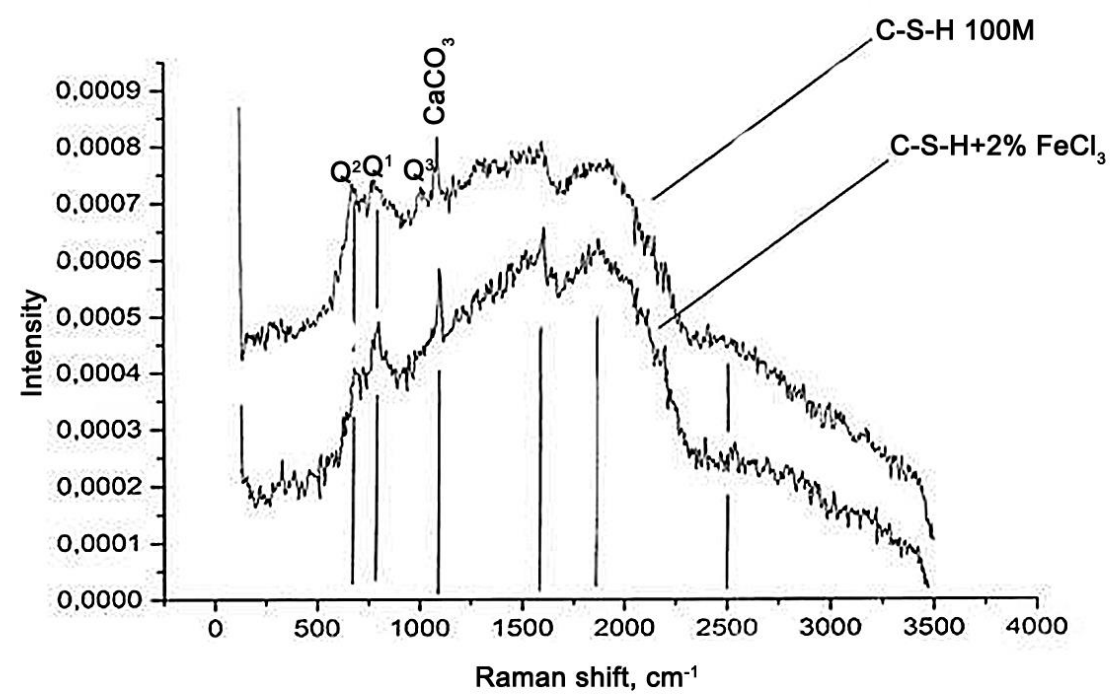

Fig. 7. Raman spectra of pressed at $100 \mathrm{MPa}$ C-S-H and it with the addition of $4 \% \mathrm{FeCl}_{3}$.

The spectrum with alumina zol is identical to the spectrum of the original C-S-H 100M, which indicates the assimilation of $\mathrm{Al}^{3+} \mathrm{C}-\mathrm{S}-\mathrm{H}$ ions by the phase.

The addition of iron chloride to C-S-H (Figure 7) redistributes the intensities of reflections of silicon-oxygen tetrahedra: the proportion of $\mathrm{Q}^{2}$ decreases, $\mathrm{Q}^{1}$ increases, $\mathrm{Q}^{3}$ disappears, and $\mathrm{Q}^{3}$ disappears. The $\mathrm{C}-\mathrm{O}$ lines in $\mathrm{CaCO}_{3}$ do not change the intensity. A line appears at $1600 \mathrm{~cm}^{-1}$, which is also characteristic of an alumina zol that was not identified with the addition of alumina zol. In general, there is an obstacle to the process of condensation of silicon-oxygen substructures in the presence of $\mathrm{FeCl}_{3}$. This probably enhances the early contact strength of hydrated cement (Figure 1), but reduces the strength of hardening cement by up to $30 \%$ [16].

As the spectrum of hydrated cement with carbon shows (Figure 8), nano-carboncontaining additives (carbons, fullerenes, nanotubes, and others) probably interact with portlandite and calcium substructures in the C-S-H phase, because major changes are noted in the area of $1500-1600 \mathrm{~cm}^{-1}$ and $2000 \mathrm{~cm}^{-1}$. 


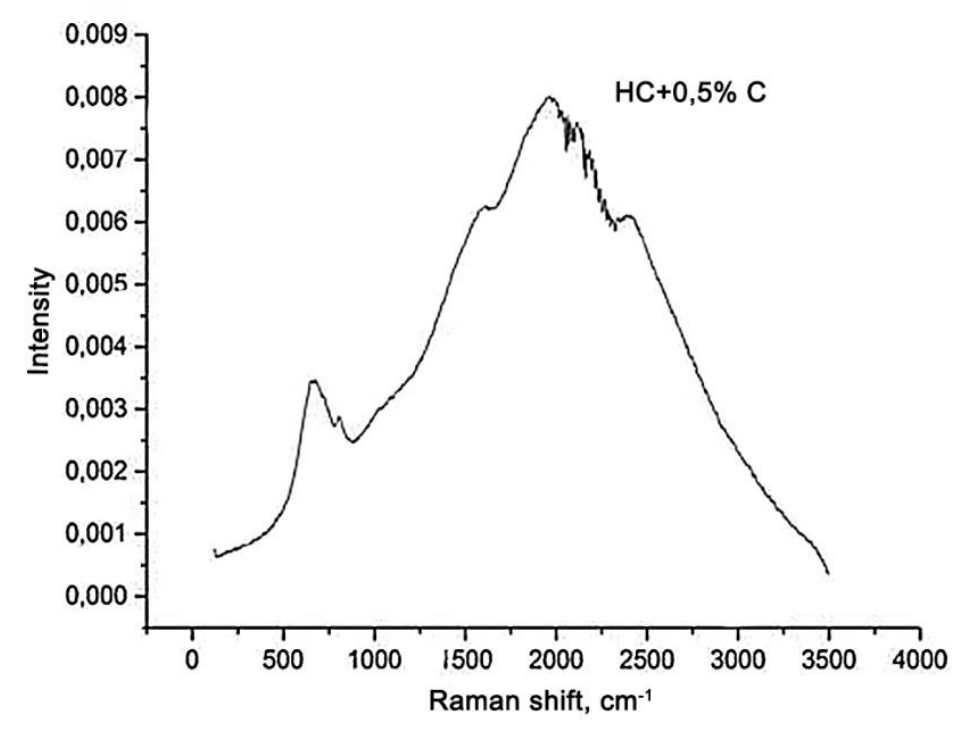

Fig. 8. Raman spectra of fully hydrated Portland cement with the addition of $0.5 \%$ carbon (C).

\section{Conclusions}

1. Pressing at $100 \mathrm{MPa}$ of the powder from the C-S-H phase without additives leads to a substantial condensation of the silicon-oxygen chains with their crosslinking. The content of $\mathrm{Q}^{2}$ tetrahedra increases significantly; $\mathrm{Q}^{3}$ tetrahedra appear. This indicates the spontaneous polymerization of silicon-oxygen anions in cement during compression.

2. Additives that increase the strength of the stone (nano-silica in the form of silica zol, nano-alumina in the form of alumina zol, silicon carbide, nano-carbon) contribute to the accumulation of tetrahedra that crosslink the silicon-oxygen chains $\mathrm{Q}^{2}$ and $\mathrm{Q}^{3}$ in $\mathrm{C}-\mathrm{S}-\mathrm{H}$.

3. Additives that do not contribute to the growth of cement stone strength, for example, iron and aluminum chlorides, significantly change the distribution of types of siliconoxygen tetrahedra. The crosslinking tetrahedra of $\mathrm{Q}^{2}$ are significantly reduced, the end tetrahedra of $\mathrm{Q}^{1}$ increase, and the crosslinking $\mathrm{Q}^{3}$ disappear. All this does not lead to an increase in the strength of the pressed stone from $\mathrm{C}-\mathrm{S}-\mathrm{H}$ and reduces the strength of the cement stone by adding $\mathrm{FeCl}_{3}$ to $30 \%$.

4. Carbon-containing nano-additives significantly change the spectrum of calcium structures in cement stone and $\mathrm{C}-\mathrm{S}-\mathrm{H}$ in the form of portlandite and calcium polyhedra.

The work was carried out under the RFBR grant 18-43-220005 "Fundamentals of strengthening cementitious properties of cement phase C-S-H".

\section{References}

1. V.B. Ratinov, T.I. Rosenberg, Additives in concrete (Stroyizdat, 1973)

2. Additives in concrete: Ref. allowance / V.S. Ramachandran, R.F. Feldman, M. Kolepardi, etc. (Stroyizdat, 1988)

3. H. Taylor, Chemistry of cement (Mir, 1996) 
4. G. Bastos, F. Patiño-Barbeito, F. Patiño-Cambeiro, Materials, 9, 1-30 (2016)

5. Z. Wu, K.H. Khayat, C. Shi., Cement and Concrete Research, 95, 247-256 (2017)

6. A. Mahawish, S.I. Ibrahim, A.H. Jawad, Journal of Civil \& Environmental Engineering, 7, 1-10 (2017)

7. Z. Li, B. Han, X. Yu, Q. Zheng, Y. Wang, Archives of Civil and Mechanical Engineering, 19(3), 615-626 (2019)

8. W. Meng, K. H. Khayat, Cement and Concrete Research, 105, 64-71 (2018)

9. A. Shamim, S. Ahmad, A. Khitab, International Journal of Strategic Engineering, 1, 48-64 (2018)

10. R. Sikora, M. Abd. Elrahman, D. Stephan, Nanomaterials, 8, 465 (2018)

11. J. J. Thomas, H. M. Jennings. Cement and Concrete Research, 36, 30-38 (2006)

12. G.I. Ovcharenko. Polzunovsky Almanac, 1, 173-177 (2018)

13. A.V. Volzhensky, Yu.S. Burov, V.S. Kolokolnikov, Mineral binders (Stroyizdat, 1986)

14. E.T. Rodriguez, I.G. Richardson. Advances in Applied Ceramics, 114, 362-371 (2015)

15. S. Ortaboy, Li Jiaqi, G. Geng, R.J. Myers, P.J.M. Monteiro. RSC advances, 7, 4892548933 (2017)

16. T.S. Shepelenko, N.P. Gorlenko, O.A. Zubkova, Engineering and Construction Journal, 5 (81), 125-134 (2018) 